\title{
The Acquisition of English Restrictive Relative Clauses by Arab Adult EFL Learners
}

\author{
Hayat Eid Alroudhan (Corresponding author) \\ Al-Imam Mohammad Ibn Saud Islamic University \\ College of Languages and Translation \\ Department of English Language and Literature \\ E-mail: hayat.alroudhan@gmail.com
}

Doi:10.7575/aiac.alls.v.7n.1p.33

Received: 23/08/2015

URL: http://dx.doi.org/10.7575/aiac.alls.v.7n.1p.33

Accepted: 01/11/2015

\begin{abstract}
This study investigates the challenges faced by Arab adult learners of English as a foreign language (EFL) in acquiring English restrictive relative clauses (RRCs), as well as the factors that affect the process of acquisition. This issue has received considerable attention in second language (L2) research. The present study discusses the syntactic structure of RRCs in English and Arabic with regard to the use of resumptive pronouns and the use of overt versus covert relative markers as related to the definiteness of the head noun. This study is carried out using an acceptability judgment test as the tool for data collection. A sample of 100 male and female adult Arabic speakers is used with the aim of identifying potential acquisition problems. The results obtained provide further support for first language (L1) transfer. This study concludes that participants accepted the use of resumptive pronouns and preferred the overt relative markers determined by definiteness. It is further discovered that certain factors influenced the acquisition process such as participants' age, age of learning, and age of immersion. The current study has some pedagogical implications for the teaching of relative clauses in the EFL context.
\end{abstract}

Keywords: English Relative Clauses, Restrictive Relative Clauses, Relative pronoun, Arab Learners of English

\section{Introduction}

The acquisition of a second language's (L2) structure often attracts researchers' interest. Most studies investigating the acquisition of a second language's complex structure have found that it is affected by a number of factors. The most common factor is generally the cross-linguistic influence of the first language (L1). Cross-linguistic transfer is a widely identified phenomenon in second language research. Many studies have provided evidence that the structural distinction between first and second languages often causes difficulties in the process of acquiring a second language's complex structure. For example, researchers such as Shaheen (2013), Algady (2013) and Zagood and Juma (2012) have examined the influence of cross-linguistic transfer between Arabic and English on the acquisition of L2 relative clauses. In other words, the previous studies have shown that Arab adult EFL learners made errors when forming relative clauses. Such repeated errors when using relative clauses to form complex sentences have led to their becoming a common issue among learners. Therefore, there is a need to conduct research in order to investigate the causes of the serious errors that hinder the ability of learners to master the complex structures of the English language generally and English restrictive relative clauses in particular. On the other hand, over the last few decades, there has been little research on the acquisition of RRCs in English. Hence, the current study was conducted to investigate the acquisition of English restrictive relative clauses (RRCs) by adult English learners with regard to the use of resumptive pronouns and the use of overt versus covert relative markers as related to the definiteness of the head noun (antecedent) as well as the different factors that may result in difficulty in that acquisition. In order to meet the purpose of this study, the following research questions were formulated:

Q1- What are the most common mistakes made by Arab adult EFL learners in acquiring English RRCs?

Q2- What are the main factors affecting the acquisition of English RRCs by Arab adult EFL learners?

\section{Literture Review}

\subsection{Defining and Non-Defining Relative Clauses}

Relative clauses generally act as subordinate clauses in complex sentences. There are two types of relative clauses: defining and non-defining. The defining relative clause is also known as the "restrictive relative clause". This type of relative clause functions as a definition for the head noun, which can be the subject or object, and such clauses are essential in the sentence. The term "restrictive" refers to essential words that define the meaning and modify the head noun by limiting the range of possible referents. Therefore, restrictive relative clauses are considered to be defining relative clauses due to their semantic function. Consequently, these clauses should not be removed or enclosed by commas, as shown in (1) below. 
1) The book that you bought is very expensive.

The other type of clause is the non-defining clause. It is also known as a "non-restrictive relative clause" because additional information is presented about the head noun. However, this type of relative clause is not necessary and that explains why it is located after or in-between comma(s), as given in (2) below.

2) This book, which is a gift from my friend, is very interesting.

\subsection{The Notion of Restrictive Relative Clauses}

The term "restrictive relative clause" is defined by the Longman Dictionary of Language Teaching and Applied Linguistics (2010) as "a clause which gives additional information about a noun or a noun phrase in a sentence [and] restricts or helps to define the meaning of the noun. It usually begins with who, which, whom, whose, or that, [also it] is not separated from the noun by a comma" (p. 159). A more specific description is given by Amer (2003), who states that "restrictive clauses are also called defining relative clauses, or identifying relative clauses as they identify the antecedent" (p. 3).

Another term connected with relative clauses is the relative pronoun (relative marker). It is described as "relat[ing] to another noun preceding it in the sentence [and] it connects a dependent clause to an antecedent (a head noun that precedes the pronoun). Therefore, a relative pronoun acts as the subject or the object of the dependent clause" (Amer, 2003 , p. 3). He also says that there are alternative options for relative pronouns, such as a wh- word, that, or zero; the choice depends on the nature of the antecedent and its relation to the dependent clause in terms of essential information.

\subsection{Restrictive Relative Clauses in English}

English RRCs are placed after the head noun (post-nominal). Accordingly, they function as an adjectival clause that modifies the preceding head noun. Meanwhile, English RRCs are introduced by a relative marker or an optional gap in object positons. According to Algady (2013), there are three cases of English RRCs that are either introduced with a wh-word, such as who, which, whom, and whose as shown in (3a) and (4a), with the complementizer that as in (3b) and (4b), or with none as in (3c). However, the omission of the relative marker takes place when the relativization is in the object position. This indicates why, when we use a sentence with a zero-relative marker as in (4c), it becomes ungrammatical because the relativization is in the subject position.

3)

a) I saw the man whom you know.

b) I saw the man that you know.

c) I saw the man you know.

4)
a) I saw a man who asked for help.
b) I saw a man that asked for help.
c) *I saw a man asked for help. ${ }^{1}$

Relative markers agree with the head noun in number but not in gender. Most relative markers do not show case endings, except for whom and whose, which are marked for accusative and genitive respectively. These relative pronouns are used as markers to differentiate between subject and object as in who and whom, and they also distinguish human from non-human as in who and which. Another feature that needs to be noted is that the head noun in RRCs can be a word or a phrase. It also can be definite as in $(3 \mathrm{a}-\mathrm{c})$ or indefinite as in $(4 \mathrm{a}-\mathrm{c})$.

A further fact noted by Al-Washali and Hasnain (2013) is the general tendency to use the relative marker that in all cases. Several researchers, such as Amer (2003), support this view because that can be used for all relativization positions as well as for people, animals and things.

\subsection{Restrictive Relative Clauses in MSA}

Relative clauses in Arabic are similar to those in English as they both follow and modify the head noun. As stated by Algady (2013), the types of relative clauses under discussion in MSA are those introduced by the equivalent of the English complementizer that (?allaðii الذي) forms. These relative pronouns have similar phonological stems but different endings with regard to the number, gender and case endings. Also, relative pronouns in Arabic are referred to as (Td'maa?uru-Plmaws ${ }^{\complement}$ ula الضمائر الموصوله), which means that they are connecting pronouns. The basic feature of MSA relativization that distinguishes it from English is that it contains a resumptive pronoun in certain cases and/or a gap in others.

Unlike the English whose and whom, the relativization system in MSA has no possessive relative marker, as discussed by Al-Washali and Hasnain (2013). Additionally, unlike the English that, no relative marker can be used in all cases. Indeed, as a result, there is a general tendency in Arabic dialects to use ( Pallii اللي), which is equivalent to that; it is used as a relative marker for all cases.

\footnotetext{
${ }^{1}$ The ${ }^{*}$ symbol indicates that the sentence is ungrammatical.
} 
Agreement in the gender and number of relative markers with the head noun in MSA can be seen in singular, dual, and plural cases. However, the case agreement only happens in dual cases (Amer, 2003; Algady, 2013; Al-Washali \& Hasnain, 2013). The sentences in (5) below show the difference for each case.

5)

a) Rallaðii masculine singular:

\begin{tabular}{|c|c|c|c|c|c|}
\hline $\begin{array}{l}\text { Pariftu } \\
\text { knew-1Sng }\end{array}$ & $\begin{array}{l}\text { P- } \mathrm{t}^{\uparrow} \text { aaliba } \\
\text { the-student-M }\end{array}$ & $\begin{array}{l}\text { Pallaðii } \\
\text { that -3MSng }\end{array}$ & $\begin{array}{l}\text { taḥada } \theta a \\
\text { talked-3MSng }\end{array}$ & $\begin{array}{l}\text { fii } \\
\text { in-Prep }\end{array}$ & $\begin{array}{l}\text { Pl-ḥafel } \\
\text { the-party }\end{array}$ \\
\hline
\end{tabular}

"I knew the student who talked in the party."

b)

Pallatii feminine singular:

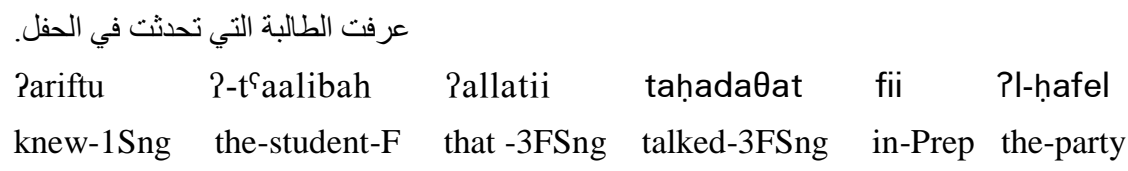

"I knew the student who talked in the party."

c)

?alladani masculine dual:

عرفت الطالبين اللذين تحدثا في الحفل.

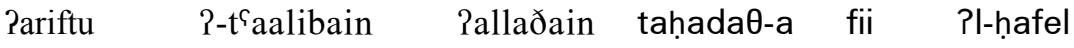

knew-1Sng the-students-M that-3MD talked-3MD in-Prep the-party

"I knew the students who talked in the party."

d) Rallatani feminine dual:

عرفت الطالبتين اللتين تحدثا في الحفل.

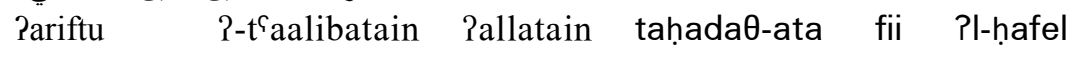

knew-1Sng the-students-F that -3FD talked-3FD in-Prep the-party

"I knew the students who talked in the party."

e) Pallaðiina masculine plural:

عرفت الطلبة الذين تحدثوا في الحفل.

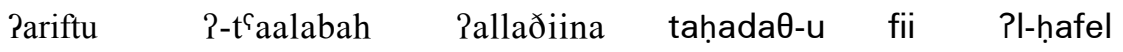

knew-1Sng the-students-M that-3MPlr talked-3MPlr in-Prep the-party

"I knew the students who talked in the party."

f) Rallawati feminine plural:

عرفت الطالبات اللو اتي تحدثن في الحفل.

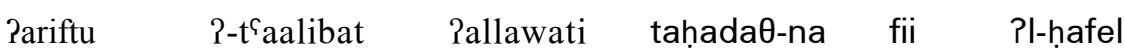

knew-1Sng the-students-F that-3FPlr talked-3FPlr in-Prep the-party

"I knew the students who talked in the party."

2.4.1 Definiteness in MSA restrictive relative clauses

Definiteness is an essential feature in MSA relativization. Algady (2013) pointed out that the use of relative markers is entirely based on the definiteness of the head noun. So, relative markers only follow the definite head noun as presented in (6a). For that reason, the indefinite head noun in (6b) is not followed by any relative marker.

6)

a)

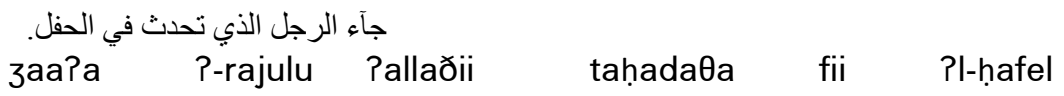

came-1Sng the-man who-3MSng talked-3MSng in-Prep the-party

"The man who talked in the party has come."

b)

$$
\text { جآء رجلّ تحدث في الحفل. }
$$

came-1Sng man-Indef. talked-3MSng in-Prep the-party

"A man who talked in the party has come."

2.4.2 Resumptive pronoun in MSA restrictive relative clauses 
Resumptive pronouns are considered to be a major feature in Arabic relative clauses. The Longman Dictionary of Language Teaching and Applied Linguistics (2010) defines resumptive pronouns as "in the position of a trace left behind when forming a wh-phrase. [...] Resumptive pronouns are ungrammatical in Standard English, but they are acceptable or obligatory in many languages (e.g. Arabic)" (p. 498). The resumptive pronoun is known as ( $\mathrm{Pad}^{\complement} \mathrm{amiru}$ 21-YaaPid (الضمير العائد Arabic, which means the pronoun returns because its function is to return the meaning to the head noun in order to fill the gap. In the literature, it is often referred to as a clitic pronoun. This resumptive pronoun in MSA functions as a referent for the head noun and is usually attached to a verb as in (7a) and (7b) or to a preposition as in (7c) in RRCs.

7)

a) Optional resumptive pronoun in the direct object position.

$$
\begin{aligned}
& \text { رأيت الرسالة التي كتبها الطالب. } \\
& \text { ra?aj-tu 2-risaalata ?allatii kataba-(ha) 2-t'aalibu } \\
& \text { saw-1Sng the-message that-3FSng wrote.3MSng-it the-student }
\end{aligned}
$$

"I saw the message that the student wrote."

b) Obligatory resumptive pronoun in the indirect object position.

$$
\text { رأيت الأستاذ الذي سلمه الطالب الرسالة. }
$$

ra?aj-tu 21-Pstaaða Rallaðii sallama-hu 2-t`aalibu 2-risaalah

saw-1Sng the-teacher that-3FSng delivered.3MSng-him the-student the-message

"I saw the teacher that the student delivered the message to."

c) Obligatory resumptive pronoun in the oblique position.

رأيت الأستاذ الذي أرسل الطالب إليه الرسالة.

$$
\text { ra?aj-tu 21-2staaða a llaðii Prsala 2-t`́aalibu 2laj-hi 2-risaalah }
$$

saw-1Sng the-teacher that-3MSng sent.3MSng the-student to-him the-message

"I saw the teacher that the student sent the message to."

The resumptive pronoun agrees with the head noun in number, gender and case. Its use is compulsory when the positions being relativized are indirect objects as shown in (7b) or obliques as in (7c). On the other hand, resumptive pronouns are optional in the direct object position as given in (7a). However, the one that occupies the subject position comes as a free subject pronoun. (For more detail regarding resumptive pronouns in MSA, see Amer (2003) and Algady (2013).)

\subsection{Similarities and Differences between English and Arabic RRCs}

As mentioned above, RRCs are practically identical in English and Arabic in their right branching, function, and the use of a relative marker at the beginning or the fact that they sometimes have a gap in certain cases. Therefore, it may be possible that learners become confused as they mix the two and produce redundant or ungrammatical English sentences, often with an overlap of the two forms. Despite several decades of research into the acquisition of English RRCs, there is still little definitive knowledge as to why these difficulties arise.

On the other hand, two major differences were noted. The first one is that the use of the relative markers in MSA RRCs depends on the definiteness of the head noun; accordingly, it is omitted after an indefinite head noun. However, the absence of relative markers in English RRCs only occurs when the relativization is in the object position. The second distinction is that English RRCs do not include a resumptive pronoun, which is considered to be the main difference between Arabic and English RRCs. In MSA, the use of a resumptive pronoun is optional in subject and direct object positions, despite being obligatory in indirect object and oblique positions as shown above in ( $7 \mathrm{a}-\mathrm{c})$.

\subsection{Recent Empirical Studies on Relative Clauses}

In viewing L1 transfer from a linguistic perspective, Shaheen (2013) argued that L1 transfer is a key concern because learners' first language influences their grammatical knowledge of the L2. This implies that learners' L1 properties are transferred to the way they approach L2 data. Therefore, it might be assumed that L1 transfer is a crucial issue when the L1and L2 have distinct universal parameters. Similarly, Zagood and Juma (2012) concluded with proof that some Libyan university students faced difficulty when translating RRCs from and into English and Arabic. This indication refers to a negative transfer of L1 since the participants displayed a general weakness regarding relative clauses in both English and Arabic.

In the case of the role of syntactic distinction, Shaheen (2013) used acceptability judgment, gap filling, and translation tasks to examine how Syrian learners acquire English RRCs. The result was that certain tested properties seem to be transferred from the L1, so there is no dominance of interference from L1. Shaheen (2013) concluded that L1 interference alone is not responsible for the difficulty of L2 acquisition; however, "there are clear cases of L1 effects particularly in the case of the persistent use of RPs. This appears to suggest that the instantiations of RRCs are still those of the L1" (p. 278). "Appears to suggest" is a vague expression here and does not express the extent to which the produced English RRCs are "still those of the L1". Shaheen (2013) suggested that the resumptive pronoun is considered the biggest issue. Where trace and movement are not issues, it is a null resumptive pronoun that creates the "gap in LSA learners' mental grammar" (Shaheen, 2013, p. 279). Learners accepted the presence and/or absence of the resumptive 
pronoun. This flexibility of learners' acceptance of the resumptive pronoun may refer to the optionality of using it in certain contexts. This agrees with what we are saying since resumptive pronouns do not exist in English RRCs. Arabic learners cannot separate the parameters of the two languages from each other most of the time, whereas it is supposed that they are able to reset the parameters in order to acquire English RRCs competently. In the same vein, Prentza's (2012) study examined the structural distinction between RRCs in Greek and English. The study investigated the acquisition of English RRCs by advanced Greek learners. Despite showing that Greek and English parameters are different regarding RRC formation, the study discussed learners' choices in relation to syntactic features. The experiment questioned the possibility of parameter resetting in adult L2 acquisition. The findings revealed that advanced Greek learners could not acquire the features of the English RRCs. Therefore, the results of the experiment fully supported recent L2 theorists' assumptions about the long-term problems of L2 acquisition due to the syntactic distinction between L1 and L2.

In the case of the language proficiency level, in a recent study, Zhu (2014) discussed the existence of differences or similarities regarding the syntactic transfer of English RCs by Chinese learners whose levels of proficiency varied. The study revealed that the syntactic transfer amount is larger for complex L2 structures in learners at a lower proficiency level, although those at a higher proficiency level tended to rely on their Chinese L1 syntactic structures.

\section{Methodology}

\subsection{Subjects}

A total of 123 subjects initially took the test. However, 23 participants were excluded. This is because two were aged 18 and the other 21 rated the same repeated item differently. The ultimate study sample therefore consisted of 100 participants, 78 females and 22 males, as shown in Table 1. All the subjects were native speakers of Arabic and they were either advanced EFL learners or English teachers. The targeted participants all specialized in the English language. The study included questions regarding background variables such as gender, age, age at first exposure to formal English instruction, and childhood immersion in English-speaking environments. Descriptions of the participants' distribution according to these variables are listed below.

Table. 1 Gender distribution of the sample $(\mathrm{N}=100)$

\begin{tabular}{lll}
\hline Category & Frequency & Percentage \\
\hline Male & 22 & $22 \%$ \\
Female & 78 & $78 \%$ \\
Total number & 100 & $100 \%$ \\
\hline
\end{tabular}

\subsubsection{Age}

The ages of the participants ranged from 20 to 51 years; frequencies and percentages are used to show the distribution of participants within the age categories in Table 2.

Table 2. Age distribution $(\mathrm{N}=100)$

\begin{tabular}{lcc}
\hline Age Category & Frequency & Percentage \\
\hline $20-29$ & 53 & $53 \%$ \\
$30-39$ & 36 & $36 \%$ \\
40 and above & 11 & $11 \%$ \\
Total number & 100 & $100 \%$ \\
\hline
\end{tabular}

\subsubsection{Age at first exposure to formal English instruction}

The participants varied in terms of their age at their first exposure to the English language through instruction. A total of $(\mathrm{n}=44)$ participants started studying English in intermediate school, $(\mathrm{n}=26)$ started in primary school, and $(\mathrm{n}=26)$ started in kindergarten in a formal classroom setting. Only four participants gave the response "other", stating that they started trying to learn English outside the classroom by watching English TV shows or that their parents tried to teach them English at home before kindergarten. The participants were divided into four categories according to when they started learning English. The frequency and percentage in each group are given in Table 3.

Table 3. Age at first exposure to formal English instruction $(\mathrm{N}=100)$

\begin{tabular}{lcc}
\hline Category & Frequency & Percentage \\
\hline Kindergarten & 26 & $26.0 \%$ \\
Primary school & 26 & $26.0 \%$ \\
Intermediate school & 44 & $44.0 \%$ \\
Other & 4 & $4.0 \%$ \\
Total number & 100 & $100 \%$ \\
\hline
\end{tabular}




\subsubsection{Childhood immersion in English-speaking environments}

The participants had similar English learning experiences, except for the 16 participants who lived in English-speaking countries at ages ranging from 1-12 years during their childhood. This factor may affect their learning of English since they were exposed to the language early in life, before the critical period, and were immersed in the English language environment. Table 4 shows the frequencies and percentages of responses to this question.

Table 4. Childhood immersion in English-speaking environments $(\mathrm{N}=100)$

\begin{tabular}{lc}
\hline Category & Frequency \\
\hline Yes & 16 \\
No & 84 \\
Total number & 100 \\
\hline
\end{tabular}

The last two variables were used to test the difference between the performance of early and late learners, as well as the influence of early immersion in English environments on the acquisition of syntactic competence. Several researchers (e.g. Alrashed, 2007) have used these variables to report significant details regarding the relevance of participants' backgrounds to their English language ability.

\subsection{Instrumentation}

An acceptability judgment test (AJT) adapted from Shaheen (2013) was used for data collection in order to investigate the participants' acquisition of English RRCs. The test was modified to examine the influence of MSA as L1 transfer on English language acquisition. The test checked participants' judgment of syntactic well-formedness by getting them to give spontaneous reactions to sentences that have RRCs. The test was selected based on the fact that it has less bias when measuring cognitive competence, and it is the preferred method for investigating questions of syntax according to Gibson and Fedorenko (2013).

In the present study, the test consisted of 45 items including 10 distractors. There were 34 main test items: 24 grammatical items to test the level of English RRC acquisition and 10 ungrammatical items, which aimed to examine the participants' realization of RRCs as well as whether they are influenced by their L1. In the test, there was one repeated item and this was supposed to check participants' concentration while performing the test. Participants were asked to rate the sentences from 1-10, where 1 meant the sentence seemed totally unacceptable and 10 meant it looked totally acceptable. The order of the AJT items was randomized (see Appendices A and B).

\subsubsection{The basic principles of the AJ T}

In the construction of the AJT, all items had the same tense (simple past). All vocabularies used are considered common among English speakers. Simple RRCs were used in order to avoid any possible ambiguity in the sentences. The basic aspects are:

\section{The use of resumptive pronouns in subject, object, and object of preposition positions.}

Unlike English, in Arabic these positions involve an obligatory resumptive pronoun except for the $\mathrm{S}$ position, which is optional. For this reason, the sentences tested for extraction of subject (S), object (O), and object of preposition (OP) positions as a means for investigating L1 transfer. These sentences are considered ungrammatical in English because they involve the use of a resumptive pronoun, although participants may tend to think that they are acceptable in all positions and particularly in place of the object. The sentences appear in questions 12, 25, 26, 30, 39, and 40 in the test.

\section{The use of overt versus covert relative markers and definiteness.}

Definite and indefinite heads of RRCs were used in all positions (i.e., S, O, and OP). This is because in MSA indefinite RRC heads disallow overt relative markers regardless of their positions. Thus, this is a potential measure of L1 influence since relative markers in English RRCs are deleted only when the relativization position is in the object position, irrespective of the definiteness of the head noun. As a result, covert and overt relative markers were included to test participants' awareness of the distribution of these forms. Potentially, participants may consider a grammatical English sentence to be unacceptable, while they may think an ungrammatical sentence is acceptable. The sentences with definite heads appear in $3,5,8,11,17,18,24,32,35,36,37$, and 44 in the test. The indefinite ones also appear in questions $2,4,10,13,14,19,21,23,28,31,41$, and 42 .

\section{The preference for using the relative marker "that".}

A scale was included to test whether there is a preference for that, since there is a general tendency in almost all Arabic dialects to use the relative marker ( Pallii اللي), which might be equivalent to that. There may be a corresponding relationship between these two aspects. The sentences that belong to this aspect appear in 9, 15, 29, and 38.

A pilot study was carried out before the final AJT in order to identify potential practical problems. The aim of the pilot study was to examine the validity, adequacy, and reliability of the instrument used in the study, as well as the administrative procedure. Some properties were restructured to avoid ambiguity on the basis of the responses from participants in the pilot study (e.g. wh- RRCs and $\varnothing \mathrm{RRCs}$ ).

The AJT was carefully designed to ensure the accuracy of the results and the appropriate layout. For illustration, the distribution of the RRC types and how many items were used to represent each aspect are summarized in Table 5 (see 
Appendices A and B for the test items). The symbol * is used before an RRC construction to identify an ungrammatical structure. When no sign is used, the RRC construction is grammatical. It should be noted here that the test did not include items involving whose because this word does not have an Arabic equivalent and it was considered important to limit the number of items tested.

Table 5. Distribution of items tested in the AJT and the items involved in each aspect

\begin{tabular}{|c|c|c|c|}
\hline Tested aspect & RRC positions & $\begin{array}{l}\text { No. of items in } \\
\text { each position }\end{array}$ & $\begin{array}{l}\text { No. of items in each } \\
\text { aspect }\end{array}$ \\
\hline \multirow[t]{3}{*}{ Resumptive pronoun } & $* S$ & 2 & 6 \\
\hline & $* \mathrm{O}$ & & \\
\hline & $* \mathrm{OP}$ & & \\
\hline \multirow{6}{*}{$\begin{array}{l}\text { Definite RRCs with overt and covert } \\
\text { relative markers }\end{array}$} & S overt & 2 & 12 \\
\hline & O overt & & \\
\hline & OP overt & & \\
\hline & $* \mathrm{~S}(\varnothing)$ covert & & \\
\hline & $\mathrm{O}(\varnothing)$ covert & & \\
\hline & OP $(\varnothing)$ covert & & \\
\hline \multirow{6}{*}{$\begin{array}{l}\text { Indefinite RRCs with overt and covert } \\
\text { relative markers }\end{array}$} & S overt & 2 & 12 \\
\hline & O overt & & \\
\hline & OP overt & & \\
\hline & *S $(\varnothing)$ covert & & \\
\hline & $\mathrm{O}(\varnothing)$ covert & & \\
\hline & $\mathrm{OP}(\varnothing)$ covert & & \\
\hline \multirow[t]{4}{*}{ Preference for using "that" } & $\mathrm{S}+$ that & 2 & 4 \\
\hline & $\mathrm{O}+$ that & & \\
\hline & $\mathrm{S}+$ wh- marker & & \\
\hline & $\mathrm{O}+$ wh- marker & & \\
\hline
\end{tabular}

\subsection{Reliability}

Cronbach's alpha was used in order to measure the reliability and consistency of the study. It also checked how closely related the items in the set were as a group to the AJT as a whole.

Table 6. Cronbach's alpha coefficient value and split half reliability

\begin{tabular}{lll}
\hline Scales & Cronbach's $\alpha$ & Split half \\
\hline Resumptive pronoun in simple RRCs & 0.845 & 0.768 \\
$\begin{array}{l}\text { Definite RRCs to test the use of overt versus covert relative } \\
\text { markers }\end{array}$ & 0.776 & 0.812 \\
$\begin{array}{l}\text { Indefinite RRCs to test the use of overt versus covert relative } \\
\text { markers }\end{array}$ & 0.636 & 0.666 \\
\begin{tabular}{l} 
Preference for using "that" \\
\hline
\end{tabular} & 0.772 & 0.793 \\
\hline
\end{tabular}

The alpha coefficient value for four sets of items is illustrated in Table 6. These values suggest fairly high reliability, which refers to the high reliability of the test tool used in the study.

4.4. Validity It was necessary to re-establish the validity of the instrument as some items were modified and some were added for the present study. The procedure for validation involved obtaining specialized expert judgment on the suitability and clarity of the instrument so as to establish the face and content validity. Assessing the internal validity included testing the Pearson correlation value of the AJT items. Each set of items is presented in a single table to show the average inter-correlation among the items. The correlation between each pair of items in the set was calculated as shown below. 
Table 7. The correlation between the item and the total scores for the resumptive pronoun dimension

\begin{tabular}{lccc}
\hline Item & Correlation Value & Item & Correlation Value \\
\hline S30 & $0.672^{* *}$ & O40 & $0.907^{* *}$ \\
S26 & $0.777^{* *}$ & OP39 & $0.819^{* *}$ \\
O12 & $0.686^{* *}$ & OP25 & $0.630^{* *}$
\end{tabular}

Note. The items consist of letters referring to the relativized positions and numbers of their order in the test.

Table 8. The correlation between the item and the total scores for the definite RRCs dimension

\begin{tabular}{lccc}
\hline Item & Correlation Value & Item & Correlation Value \\
\hline S44 & $0.513^{* *}$ & OØ37 & $0.758^{* *}$ \\
S35 & $0.774^{* *}$ & OØ3 & $0.731^{* *}$ \\
SØ24 & $0.238^{*}$ & Op32 & $0.797^{* *}$ \\
SØ36 & $0.296^{*}$ & Op11 & $0.415^{* *}$ \\
O8 & $0.776^{* *}$ & OpØ5 & $0.767^{* *}$ \\
O18 & $0.782^{* *}$ & OpØ17 & $0.589^{* *}$ \\
\hline
\end{tabular}

Table 9. The correlation between the item and the total scores for the indefinite RRCs dimension

\begin{tabular}{clcr}
\hline Item & Correlation Value & \multicolumn{1}{c}{ Item } & Correlation Value \\
\hline S14 & $0.568^{* *}$ & OØ28 & $0.556^{* *}$ \\
S31 & $0.643^{* *}$ & OØ13 & $0.649 * *$ \\
Sø4 & $0.395^{* *}$ & Op23 & $0.703 * *$ \\
Sø41 & $0.342^{* *}$ & Op10 & $0.720^{* *}$ \\
O19 & $0.543^{* *}$ & OpØ42 & $0.507 * *$ \\
O2 & $0.495^{* *}$ & OpØ21 & $0.639^{* *}$ \\
\hline
\end{tabular}

Table 10. The correlation between the item and the total scores for the preference for "that" dimension

\begin{tabular}{lllc}
\hline Item & Correlation Value & Item & Correlation Value \\
\hline A29 & $0.715^{* *}$ & A15 & $0.728^{* *}$ \\
A38 & $0.836 * *$ & A9 & $0.816^{* *}$ \\
\hline
\end{tabular}

It can be noted that the correlation values for all the four dimensions in Tables 7, 8, 9, and 10 are high, which means that all the items in the AJT have relatively high internal consistency and validity.

\subsection{Procedure}

After ensuring that the AJT questions were carefully planned and piloted, the test was designed online using Google forms. The purpose of this choice was that the test could be easily distributed to participants, and it was accessible to everyone at any time. Besides the simplicity of the test's administration, the test can be taken at both parties' convenience. Above all, this kind of test respects the participants' anonymity and confidentiality, so it guarantees the avoidance of ethical issues. At first, a brief description of the test with a link to the test website was sent to selected participants so that they could complete the test. They were informed that participation was voluntary. At the end of the test, participants were then asked to give their permission to be part of the study by clicking the submit button. A duration of two weeks was allocated for data collection to allow for reasonable flexibility. Data was collected electronically by the researcher for analysis.

\section{Results and Discussion}

\subsection{Results}

\subsubsection{Resumptive Pronoun Use in RRCs}

The results for RRCs that involved a resumptive pronoun are presented in this section. The mean ratings and standard deviations of each item are displayed below in Table 11 (see Appendix C, Table C1 for individual results). 
Table11. The mean ratings for resumptive pronoun items

\begin{tabular}{lcc}
\hline Item & M & SD \\
\hline S30 & 7.33 & 3.24 \\
S26 & 6.50 & 3.47 \\
O12 & 6.71 & 3.42 \\
O40 & 5.50 & 3.68 \\
OP39 & 5.29 & 3.75 \\
OP25 & 5.21 & 3.47 \\
\hline
\end{tabular}

As can be seen in Table 11, the mean scores show that resumptive pronoun items were highly rated. Even the individual results show that only very few participants within each item rejected the resumptive pronoun. The mean ratings for the total $\mathrm{S}, \mathrm{O}$, and $\mathrm{OP}$ positions are shown in Table 12.

Table 12. The mean rating for the total resumptive pronoun items for each position

\begin{tabular}{lllc}
\hline RRC positions & M & SD & Order \\
\hline S & 13.83 & 5.71 & 1 \\
$\mathrm{O}$ & 12.21 & 6.14 & 2 \\
OP & 10.50 & 6.26 & 3 \\
\hline
\end{tabular}

Comparisons of the mean scores show that a few participants rejected the resumptive pronoun in all three positions. Actually, the participants' rejections tended to decrease as they moved across the positions. This shows that the S position was significantly the highest in terms of rejecting the resumptive pronoun. However, the participants show acceptance toward using the resumptive pronoun in the $\mathrm{O}$ and OP positions, respectively.

\subsubsection{Definite RRCs with Overt and Covert Relative Markers}

This section reports the ratings given by participants for the overt and covert relative markers. The mean ratings and the standard deviations for the three types of RRC positions in both options are provided in Table 13 (see Appendix C, Table C2 for individual results).

Table 13. The mean ratings for definite RRC items

\begin{tabular}{lll}
\hline Item & M & SD \\
\hline $\mathrm{S} 44$ & 4.56 & 3.21 \\
$\mathrm{~S} 35$ & 7.43 & 3.03 \\
$\mathrm{~S} \varnothing 24$ & 7.68 & 2.97 \\
$\mathrm{~S} \varnothing 36$ & 7.00 & 3.20 \\
$\mathrm{O} 8$ & 8.16 & 2.91 \\
O 18 & 8.30 & 2.59 \\
O Ø 37 & 7.76 & 3.22 \\
O Ø 3 & 7.62 & 3.30 \\
OP 32 & 7.93 & 2.79 \\
OP 11 & 4.75 & 3.53 \\
OP Ø 5 & 7.44 & 3.13 \\
OP Ø 17 & 5.18 & 3.33 \\
\hline
\end{tabular}

The mean scores show that $\mathrm{L} 2$ learners accepted the overt relative marker more than the covert for the $\mathrm{O}$ and $\mathrm{OP}$ positions, but not for the $\mathrm{S}$ positions. The results of the mean ratings of participants for the total $\mathrm{S}, \mathrm{O}$, and OP positions with overt and covert relative marker forms are given in Table 14 below. 
Table 14. The mean rating for the total definite RRC items for each position

\begin{tabular}{lllc}
\hline RRC positions & $\mathrm{M}$ & $\mathrm{SD}$ & Order \\
\hline $\mathrm{S}$ & 11.99 & 5.24 & 6 \\
$\mathrm{~S} \varnothing$ & 14.68 & 5.18 & 3 \\
$\mathrm{O}$ & 16.46 & 4.73 & 1 \\
$\mathrm{O} \varnothing$ & 15.38 & 5.68 & 2 \\
$\mathrm{OP}$ & 12.68 & 5.14 & 4 \\
OP $\varnothing$ & 12.62 & 5.34 & 5 \\
\hline
\end{tabular}

A few participants were likely to accept the covert relative marker in the S position, yet the rest tended to highly reject it when the learners could identify and were aware of the English structure. However, the overt relative marker in the $S$ position showed low ratings, so it was not highly accepted. On the contrary, participants showed a high acceptance of the overt relative marker in the $\mathrm{O}$ positions. Thus, in the OP positions, participants favored the overt slightly more than the null form.

\subsubsection{Indefinite RRCs with Overt and Covert Relative Markers}

The results of RRCs with indefinite heads for the three positions are displayed in Table 15. The mean ratings and the standard deviations with the two forms of overt and covert relative markers are included (see Appendix C, Table C3 for individual results).

Table 15. The mean ratings for indefinite RRC items

\begin{tabular}{lll}
\hline Item & $\mathrm{M}$ & $\mathrm{SD}$ \\
\hline $\mathrm{S} 14$ & 6.69 & 3.28 \\
$\mathrm{~S} 31$ & 7.50 & 3.05 \\
$\mathrm{~S} \varnothing 4$ & 6.12 & 3.46 \\
$\mathrm{~S} \varnothing 41$ & 8.22 & 2.68 \\
$\mathrm{O} 19$ & 6.16 & 3.65 \\
$\mathrm{O} 2$ & 7.61 & 2.86 \\
$\mathrm{O} \varnothing 28$ & 4.03 & 3.35 \\
O Ø 13 & 7.59 & 3.07 \\
OP23 & 6.38 & 3.12 \\
OP10 & 6.68 & 3.29 \\
OP Ø 42 & 4.63 & 3.16 \\
OP Ø 21 & 5.58 & 3.32 \\
\hline
\end{tabular}

In general, the results presented in the above table show a strong tendency towards accepting the $\mathrm{S}$ position structure, with just a few exceptions. Moreover, gaps were mostly rejected within the $\mathrm{O}$ and $\mathrm{OP}$ positions. These results suggest that, as in the case of the $\mathrm{O}$ and $\mathrm{OP}$, the overt form is highly rated. This means that it is more highly accepted than the null form, which is not a favored option since it is less accepted. The mean ratings of participants for the total S, O, and OP positions with the two forms are displayed below in Table 16.

Table. 16 The mean rating for the total indefinite $\mathrm{RRC}$ items for each position

\begin{tabular}{lllc}
\hline RRC positions & $\mathrm{M}$ & $\mathrm{SD}$ & Order \\
\hline $\mathrm{S}$ & 14.19 & 5.34 & 2 \\
$\mathrm{~S} \varnothing$ & 14.34 & 5.06 & 1 \\
$\mathrm{O}$ & 13.77 & 4.92 & 3 \\
$\mathrm{O} \varnothing$ & 11.62 & 5.29 & 5 \\
OP & 13.06 & 5.26 & 4 \\
OP $\varnothing$ & 10.21 & 5.10 & 6 \\
\hline
\end{tabular}


It is clear that, to some extent at least, participants rated the overt form higher than the covert one in the $\mathrm{O}$ and OP positions; thus, they favored the overt relative marker in these positions. On the other hand, the $\varnothing$ form is preferred in the $\mathrm{S}$ position more than the overt form, except for a very few participants.

\subsubsection{Preference for Using "That"}

Here, participants were tested regarding their preference for the relative marker that over other markers. That might have been expected to be the favored form because it could be equivalent to (?allii اللي ) in Arabic dialects. The mean ratings and standard deviations are presented in Table 17 below (see Appendix C, Table $\mathrm{C} 4$ for individual results).

Table 17 The mean ratings for "that" preference items

\begin{tabular}{lll}
\hline Item & $\mathrm{M}$ & $\mathrm{SD}$ \\
\hline that 29 & 7.59 & 3.27 \\
who 9 & 8.49 & 2.79 \\
that 38 & 7.98 & 2.96 \\
which 15 & 6.94 & 3.36 \\
\hline
\end{tabular}

From the results above, almost all participants accepted all instances for the two sentences. In the first sentence, they rated who higher than that, but in the second one that was rated higher than which. The total means of the ratings were calculated as shown in Table 18 below, where that appears to be slightly higher than the other markers; therefore, that is likely the preferred option.

Table 18. The mean rating for the total "that" items and the other relative markers

\begin{tabular}{llll}
\hline Relative marker & $\mathrm{M}$ & $\mathrm{SD}$ & Order \\
\hline that & 15.57 & 5.25 & 1 \\
who + which & 15.43 & 5.18 & 2 \\
\hline
\end{tabular}

\subsubsection{Gender}

The results of the t-test found a non-significant effect for differences between males and females in the resumptive pronoun use and the use of overt and the covert relative markers.

4.1.6 Age

A one-way ANOVA was used to test the behavior of age groups. Table 19 below shows the results of between and within group differences in order to illustrate how divergent individual behavior within each age group is (see Appendix C, Table C5 for individual results).

Table 19. One-way ANOVA to determine the differences between age groups

\begin{tabular}{lll}
\hline Tested aspects & $F$ & $P$-value \\
\hline Resumptive Pronoun & 2.548 & Not Sig. \\
Definite RRCs & 0.985 & Not Sig. \\
Indefinite RRCs & 0.593 & Not Sig. \\
"That” Preference & 1.405 & Not Sig. \\
Object & 3.737 & 0.05 \\
\hline
\end{tabular}

The above results show that not all aspects were statistically significant, with the exception that the effect of the object positions shows significant differences at 0.05 between age groups. As a result, the least significant difference (LSD) test was also used to measure the different direction of the object position. Table 20 illustrates the results of this procedure.

Table 20. LSD value correlations with age groups for the object position

\begin{tabular}{llllll}
\hline \multirow{2}{*}{ Variables } & \multirow{2}{*}{$\mathrm{M}$} & $\mathrm{SD}$ & \multicolumn{2}{l}{ LSD } \\
\cline { 5 - 6 } & & & & 2 & 3 \\
\hline \multirow{3}{*}{ object } & $20-29$ & 44.075 & 7.658 & $4.408^{*}$ & 0.439 \\
& $30-39$ & 39.666 & 8.109 & & 3.969 \\
& 40 and above & 43.636 & 5.352 & & \\
\hline
\end{tabular}

*Sig. $0.05 \quad * * 0.01$


The results presented above only show a difference for two groups (20 - 29 and $30-39)$ in which the first performed differently with a 0.05 significance and showed better recognition of the English structure in the object position. However, there were no significant differences between the other groups.

\subsubsection{Age at First Exposure to Formal English Instruction}

The Kruskal-Wallis H Test was used to determine whether there are statistically significant differences between the four groups of first exposure to formal instruction. This test suited the nature of the AJT since participants measure a continuous scale from 1-10. The ratings of the groups differed, and these differences were determined as shown in Table 21.

Table.21. Kruskal-Wallis for the differences between groups for the age of learning

\begin{tabular}{llllll}
\hline Tested Aspects & $\mathrm{M}$ & $\mathrm{SD}$ & $d f$ & $\chi^{2}$ & P-value \\
\hline Resumptive Pronoun & 36.54 & 16.09 & 3 & 13.541 & 0.004 \\
Definite RRCs & 83.81 & 19.13 & 3 & 3.117 & Not Sig \\
Indefinite RRCs & 77.19 & 18.10 & 3 & 2.776 & Not Sig \\
"That” Preference & 31.00 & 9.40 & 3 & 1.491 & Not Sig \\
Subject $\varnothing$ & 29.02 & 9.32 & 3 & 16.319 & 0.001 \\
\hline
\end{tabular}

$\chi^{2}=$ Chi-square

The above comparison of the findings shows the differences between the four groups. There was a statistically significant difference at 0.004 in the use of the resumptive pronoun, unlike the other aspects that had no significance. With regards to the relativized positions, only the subject with the null relative marker presented a significant effect. Thus, an additional LSD test was required to compare the differences between the participants' judgments. Table 22 below displays the results.

Table 22. LSD value correlations between groups for age of learning in resumptive pronoun and null subject position

\begin{tabular}{|c|c|c|c|c|c|c|}
\hline \multirow{2}{*}{ Variables } & & \multirow{2}{*}{ M } & \multirow{2}{*}{ SD } & \multicolumn{3}{|l|}{ LSD } \\
\hline & & & & 2 & 3 & 4 \\
\hline \multirow{4}{*}{$\begin{array}{l}\text { Resumptive } \\
\text { Pronoun }\end{array}$} & Primary & 33.615 & 15.628 & 0.797 & 9.153* & $22.384 * *$ \\
\hline & Intermediate & 32.818 & 16.463 & & $9.951 * *$ & $23.181 * *$ \\
\hline & Kindergarten & 42.769 & 13.336 & & & 13.230 \\
\hline & Others & 56.000 & 5.656 & & & \\
\hline \multirow[t]{4}{*}{ Subject $\varnothing$} & Primary & 27.769 & 7.596 & 1.337 & $5.653 *$ & 9.230 \\
\hline & Intermediate & 26.431 & 10.153 & & $6.991 *$ & $10.568^{*}$ \\
\hline & Kindergarten & 33.423 & 7.874 & & & 3.576 \\
\hline & Others & 37.000 & 2.581 & & & \\
\hline
\end{tabular}

*Sig. $0.05 \quad * * 0.01$

The test results revealed that the comparison between the primary and the kindergarten groups was significant $(p=$ 0.05), and the distinction indicated that the kindergarten group showed higher rejection of cases that involve a resumptive pronoun in their judgment. However, the results displayed a highly significant distinction between the primary group and the others at $p=0.01$, since the others outperformed in their rejection of the resumptive pronoun cases. On the other hand, the intermediate group showed high significance at $p=0.01$ when it was compared to the kindergarten group, and the kindergarten group performed better in the resumptive pronoun rejection. Significance was also found in a comparison of the intermediate group with the others at $p=0.01$, where the others were significantly higher than the intermediate group in terms of rejecting the resumptive pronoun.

Equally important comparisons were conducted to check the differences between the groups' performance in the null subject position. The comparisons showed that the primary group was significantly lower than the kindergarten group in terms of accepting this structure in the case of the null relative marker $(p=.005)$. A significant distinction was also found in which the intermediate group was lower than the kindergarten group and the others at $p=.005$. Even though these significant distinctions were found, there were no significant differences between the rest of the groups.

\subsubsection{Childhood Immersion in English-Speaking Environments}

A t-test was carried out to compare the judgements of those participants who were immersed in an English-speaking environment during their childhood with those who were not. The mean ratings and standard deviations for both groups with $t$ and $p$ values were measured as displayed in Table 23 below. 
Table.23. The results of the $\mathrm{t}$-test for the age of immersion

\begin{tabular}{llllllll}
\hline $\begin{array}{l}\text { Tested } \\
\text { Aspects }\end{array}$ & $\begin{array}{l}\text { Non-immersed }(\mathrm{n}= \\
\mathrm{M}\end{array}$ & $\mathrm{SD}$ & $\mathrm{M}$ & $\mathrm{Immersed}(\mathrm{n}=16)$ & $d f$ & $t$ & $P$-value \\
& $\mathrm{M}$ & & & & \\
\hline $\begin{array}{l}\text { Resumptive } \\
\text { Pronoun }\end{array}$ & 35.50 & 16.14 & 42.00 & 15.16 & 98 & 1.489 & Not Sig. \\
$\begin{array}{l}\text { Definite } \\
\text { RRCs }\end{array}$ & 82.17 & 19.67 & 92.37 & 13.38 & 98 & 1.983 & 0.05 \\
$\begin{array}{l}\text { Indefinite } \\
\text { RRCs }\end{array}$ & 75.95 & 18.05 & 83.68 & 17.48 & 98 & 1.578 & Not Sig. \\
"That" & 30.73 & 9.58 & 32.37 & 8.55 & 98 & 0.636 & Not Sig. \\
$\begin{array}{l}\text { Preference } \\
\text { Object }\end{array}$ & 41.51 & 7.73 & 47.31 & 6.59 & 98 & 2.808 & 0.006 \\
Subject & 38.71 & 8.46 & 46.81 & 8.30 & 98 & 3.516 & 0.001 \\
\hline
\end{tabular}

From the table above, the findings present a non-significant effect on the tested aspects, with the exception of definite RRCs. The immersed group score of $M=92.37$ was significantly higher than the non-immersed score of $M=82.17$, with a significance of $p=0.05$. Although both groups highly accepted the subject and object relativization positions, the immersed group seemed to be more aware of the English RRC structure with a high significance of $p=0.006$ for the object and $p=0.001$ for the subject.

4.1.9 Variables Correlation

A regression analysis was also conducted in order to examine the relationship and significant interaction between the dependent and independent variables. The coefficient correlations are displayed below in Table 24.

Table 24. Regression analysis for variables coefficient determination

\begin{tabular}{|c|c|c|c|c|c|c|c|}
\hline Dependent & Independent & $\mathrm{R}$ & $\mathrm{R}^{2}$ & F \& Sig. & T \& Sig. & Beta & $\mathrm{B}$ \\
\hline \multirow{4}{*}{$\begin{array}{l}\text { Resumptive } \\
\text { Pronoun }\end{array}$} & Age & 0.371 & 0.137 & $3.78 * *$ & $2.13^{*}$ & $0.204-$ & -4.794 \\
\hline & Gender & & & & 0.306 & 0.03 & 1.143 \\
\hline & Learning Age & & & & $2.611^{*}$ & 0.259 & 5.050 \\
\hline & Immersion Age & & & & 0.835 & 0.083 & 3.642 \\
\hline \multirow[t]{4}{*}{ Definite RRCs } & Age & 0.214 & 0.046 & 1.139 & -0.367 & -0.037 & -1.034 \\
\hline & Gender & & & & 0.715 & 0.073 & 3.340 \\
\hline & Learning Age & & & & -0.314 & -0.033 & -0.760 \\
\hline & Immersion Age & & & & 0.194 & 0.194 & 10.062 \\
\hline \multirow[t]{4}{*}{ Indefinite RRCs } & Age & 0.188 & 0.035 & 0.868 & 0.947 & 0.096 & 2.537 \\
\hline & Gender & & & & 0.246 & 0.025 & 1.093 \\
\hline & Learning Age & & & & -0.199 & -0.021 & -0.458 \\
\hline & Immersion Age & & & & 1.476 & 0.156 & 7.658 \\
\hline \multirow[t]{5}{*}{ "That" Preference } & & 0.133 & 0.018 & 0.431 & & 0.112 & 1.544 \\
\hline & Age & & & & 1.100 & 0.031 & 0.695 \\
\hline & Gender & & & & 0.298 & -0.009 & -0.107 \\
\hline & Learning Age & & & & -0.089 & 0.058 & 1.485 \\
\hline & Immersion Age & & & & 0.546 & & \\
\hline
\end{tabular}

*Sig. $0.05 \quad * * 0.01$

This section focused on the variables' correlation effect. As shown in the above table, the analysis only found a significant effect in the resumptive pronoun with the age and the age of learning, where the correlation coefficient value is $13.7 \%$. A negative relationship occurred between using the resumptive pronoun and the participants' age; thus, the 
tendency for older participants to use the resumptive pronouns appears to be greater than for those who are younger and vice versa. On the other hand, a positive relationship was found between the age of learning and using the resumptive pronoun, as participants who started learning English later increased their use of the resumptive pronoun, unlike those who started learning earlier.

As for the other variables, the coefficient correlation values are lower than the first one. Definite RRCs' contribution to the correlation rated $4.6 \%$ and the indefinite RRCs were rated 3.5\%. However, the lowest rating was $1.8 \%$ for the that preference.

\subsection{Discussion}

4.2.1 The most common mistakes made by adult EFL learners when acquiring English restrictive relative clauses are as follows.

\section{Participants accepted resumptive pronouns.}

The results of the between-subject comparisons show that there is an increased acceptance of resumptive pronouns in the cases of S, O, and OP RRCs. One possible explanation for this result is that it is evidence of L1 transfer when participants cannot differentiate between the two RRC structures. Participants could not learn gaps and so, it is here assumed, did not realize that the English language has gaps and does not use resumptives. Accordingly, this result might be explained by the fact that the progressive tendency to use the resumptive pronoun is related to its use in MSA. The reason for this relation might stem from the case of the $\mathrm{S}$ position, which has the highest rejection rating because its use is always optional in MSA. The rejection rating of the $\mathrm{O}$ position is lower than that of the $\mathrm{S}$ position, so the resumptive pronoun has a higher acceptance. This acceptance might be related to its optional use in the direct $\mathrm{O}$ position but obligatory use in the indirect $\mathrm{O}$ position in MSA. The OP position has the lowest rejection rating and is the most accepted one, which can be accounted for by the obligatory use of the resumptive pronoun in the OP position in MSA.

It might also be argued that participants judged the resumptive pronoun cases as acceptable simply because they wanted to make a connection in order to resolve ambiguity by referring to the head noun, not because they have the resumptives in their L1. However, this argument is questionable because there is no evidence proving its applicability in this study. Another possible explanation is that participants need sufficient time and frequency to become familiar with gaps in English. They might eventually realize that English has gaps in these positions and become sensitive to these frequencies. Participants, thus, could arrive at a clear recognition that English favors gaps over resumptives. One can therefore propose that the frequency of this construction in the input might be low and that the participants have not seen enough evidence that resumptives are not allowed in English.

These results confirm those observed in earlier studies, such as Shaheen's (2013) finding of a similar, progressive acceptance of resumptives in the $\mathrm{S}, \mathrm{O}$, and $\mathrm{OP}$ positions unless subjects with low proficiency allowed more resumptives than those in more proficient groups. The results of the present study are also in agreement with the findings of Zagood and Juma (2012) because learners frequently used the resumptive pronoun in translation. This practice could be considered negative transfer from the participants' L1.

\section{There was a preference for the overt relative markers in English determined by definiteness.}

The results of the total mean ratings for both definite and indefinite RRC items are displayed in Table 25. These results show that participants preferred the overt relative markers over the covert relative markers in definite RRCs. As an exception, participants showed no preference for the overt relative markers in the subject position. However, this preference for the overt form was increased in indefinite RRCs, except for the relativized null subject position where it was marginally preferred in indefinite RRCs.

Tablen25. Mean ratings distinction for definite and indefinite RRC items

\begin{tabular}{lcccc}
\hline Definite Positions & $\mathrm{M}$ & \multicolumn{2}{c}{ Indefinite Positions } & $\mathrm{M}$ \\
\hline $\mathrm{S}$ & 11.99 & & $\mathrm{~S}$ & 14.19 \\
$\mathrm{~S} \varnothing$ & 14.68 & $\mathrm{~S} \varnothing$ & & 14.34 \\
$\mathrm{O}$ & 16.46 & & $\mathrm{O}$ & 13.77 \\
$\mathrm{O} \varnothing$ & 15.38 & $\mathrm{OO}$ & & 11.62 \\
$\mathrm{OP}$ & 12.68 & & OP & 13.06 \\
OP $\varnothing$ & 12.62 & OP $\varnothing$ & & 10.21 \\
\hline
\end{tabular}

There are a number of possible explanations for these results. First, it can be argued that it is simply an apparent L1 transfer case. In the case of definite RRCs, the findings, to some extent, provide evidence of L1 transfer manifested in participants' preference for overt relative markers because in MSA it is the only option available when the head noun of the RRC is definite. The second possible explanation is that this preference is the effect of input exposure. The overt form can easily be identified as the default form for relative clauses, so participants show a tendency to prefer this form. However, this explanation assumes that the frequency of the overt form is what led learners to favor it over the covert one. The third possibility is that participants tended to reject the null form because they could not identify it as the 
default form for relatives. This tendency might be due to the overall sequence of syntactic development stages because this particular structural property can here be assumed to be more complex and difficult to acquire. Therefore, there is no clear evidence to support any of these assumptions.

One last possibility concerning the high acceptance rate for the covert form in the subject position can be offered here. This result might be explained by the fact that participants came to recognize that the covert form is not common in the subject position in English. These results are consistent with those of Zagood and Juma (2012), who found that learners misused relative pronouns with indefinite antecedents and, consequently, made errors that led to ungrammatical structures. The results of Shaheen (2013) showed that as learners became more proficient, they gradually recognized that the optionality of using the relativizer in English depends on the relativized position, instead of definiteness of the head. Shaheen's (2013) results differ from the findings presented here, although the reason for this difference is not clear.

4.2.2. The most common factors involved in the acquisition of English restrictive relative clauses by adult EFL learners are as follows.

\section{The age of participants seems to have affected their use of the resumptive pronoun.}

It is somewhat surprising that age was noted to have influenced participants' performance. There is an observed correlation between older participants and increased acceptance of using resumptives. Younger participants had a lower acceptance of using resumptive pronouns than the older ones. It is difficult to explain this result, but this higher tendency among older participants could be attributed to their relatively late exposure to the English language. Another possible explanation is older participants' infrequent use of the language due to their age. However, this result has not been previously discussed in the literature.

\section{The age at first exposure to formal instruction appears to be related to the use of the resumptive pronoun.}

Participants' age of learning could be at play here. The results of this study indicate that early exposure to English learning appears to have a positive influence on reducing the use of the resumptive pronoun. Participants who started learning English later are likely to show higher acceptance of using the resumptive pronoun compared to those who started learning earlier. The reason for this difference might stem from parameter resetting because early learning might increase learners' ability to distinguish between the L1 and L2 structural properties. These results corroborate the ideas of Shaheen (2013) and Prentza (2012), who both suggested that adult L2 learners could not separate the parameters of the two languages. Accordingly, this possible involvement of parameter resetting in the acquisition of the features of English RRCs might be based on early exposure to the English language, which could enable learners to reset the parameters of syntactic distinction between L1 and L2.

\section{Childhood immersion results in a progressive recognition of the English RRCs' structure.}

The present study found that participants who were immersed in an English-speaking environment during their childhood appeared to be more aware of the English RRCs' structure than the non-immersed. This result could be explained by the fact that immersion before the critical period might simplify the acquisition of the English RRCs' structure and the ability of parameter resetting. This factor has apparently not been examined in earlier research.

\section{Conclusion and Pedagogical Implications}

This study examined the problems that Arab adult EFL learners encounter during the acquisition of English RRCs. It also attempted to identify the factors affecting the acquisition process. The conclusion reached in this study is that learners seem to be troubled by L1 negative transfer. It is evident from the findings that the learners made some common mistakes, including the acceptance of using resumptive pronouns and a preference for the overt relative markers determined by definiteness. The current findings clearly support the relevance of several factors: participants' age, age of learning, and age of immersion. These factors are responsible for and correlated with participants' performance. These findings increase the understanding of the problems adult EFL learners face and add to the growing body of literature on the factors that influence the acquisition of English RRCs' structure. Some pedagogical implications for the teaching of relative clauses in the EFL context are discussed in the following lines:

\subsection{Integration of communicative teaching with form-focused instruction.}

The integration can facilitate learning and increase learners' ability to avoid the most frequent problem encountered by Arabic learners, namely pronoun retention. It is important to point out learners' tendency to generalize less marked RC types. Then, the use of instruction is assumed to facilitate the comprehension process.

This practical recommendation was supported by previous research, which dealt with different treatment types. For example, Ammar and Lightbown (2004) focused primarily on L2 acquisition through the instruction targeting marked relative clauses. Their study involved three experimental groups of Arabic speakers in Tunisia who were learning English. Ammar and Lightbown's (2004) findings are especially interesting because they reveal the positive effect of acquiring an English relativization system. In fact, this instructed learning helped the learners to differentiate between the Arabic and the English relativization systems. In a study on teaching English RRCs, Cheng (2007) investigated the effects of integrating form-focused instruction with communicative teaching. The study suggested that the integration of communicative activities in teaching strategies has benefits for simplifying learners' comprehension and production. 
5.2 Implementation of various communicative tasks in the classroom to enhance the learning process

English RC acquisition is considered a common L2 difficulty faced by speakers of several first languages, so Izumi and Izumi (2004) attempted to identify a helpful solution. They tested the effects of an instructional technique by investigating the possibility of allowing participants with different native languages (Arabic, French, German, Italian, Spanish, Turkish, Japanese, Korean, and Thai) to produce oral output as a means of acquiring ERCs (Izumi \& Izumi, 2004). The oral output tasks took the form of oral descriptions of 24 pictures after their appearance on a screen. The non-oral output group arranged the pictures into a particular order and then answered questions about them instead of describing them. Contrary to expectations, Izumi and Izumi (2004) concluded that the oral output group "failed to outperform" (p. 587) the non-output group. Although, the treatment in this study failed, it may work under different circumstances or with modification.

\section{Suggestions for Future Research}

Based on the above conclusion, some recommendations for the future investigation of adults' L2 acquisition of the RRC structure are made. This structure has been the subject of interest in research studies over the past few years, although almost none have considered the influence of the critical period on the acquisition process. The findings of the present study provide the following insights for future research.

1. The preference for overt relative markers with definite heads is an important issue that needs further exploration.

2. It is suggested that future studies investigate the association of RRC acquisition with the factors of age of learning and age of immersion.

3. In future work, this study could be replicated with a wider scope to explore whether these findings are applicable across nations.

4. This study focused on Arabic-speaking, adult EFL learners. Additional studies should be conducted to explore whether these factors affect speakers of other L1 languages.

\section{References}

Alrashed, M. (2007). Ultimate Attainment of Pronunciation after Puberty in Second Language (Unpublished master's thesis). Arizona State University, Arizona, United States.

Al-Washali, I. H. N. M., \& Hasnain, S. I. (2013). A comparative study on relative clause structure in English and Arabic. Language in India, 13(3), $1 . \quad$ Retrieved from http://go.galegroup.com/ps/i.do?id=GALE\%7CA323349798\&v=2.1\&u=sdl\&it=r\&p=AONE\&sw=w\&asid=4c3fc4bfce b10e580dc3ef0e5089d433

Amer, W. M. (2003). On the Syntactic and Semantic Structure of Relative Clauses in English and Arabic: A Contrastive Study. Unpublished manuscript, Islamic University of Gaza.

Ammar, A., \& Lightbown, P. (2004) Teaching marked linguistics structures: More about the acquisition of relative clauses by Arab learners of English. In A. Housen \& M. Pierrard (Eds.), Studies on Language Acquisition: Investigations in Instructed Second Language Acquisition. Berlin, DEU: Walter de Gruyter.

Cheng, Y. C. (2007). The Effects of Two Teaching Methodologies on the Hierarchy of Difficulty of Restrictive Relative Clauses among Taiwanese Tenth Graders. Linguistics Journal, 2(3), 72-107.

El-Badarin, M. N. (1982). Transfer, strategies, and structural complexity in the acquisition of English syntax by Arabic speakers.

Gibson, E., \& Fedorenko, E. (2013). The need for quantitative methods in syntax and semantics research. Language and Cognitive Processes, 28(1-2), 88-124. doi:10.1080/01690965.2010.515080

Izumi, S. (2003). Processing difficulty in comprehension and production of relative clauses by learners of English as a second language. Language Learning, 53(2), 285-323.

Izumi, Y., \& Izumi, S. (2004). Investigating the effects of oral output on the learning of relative clauses in English: Issues in the psycholinguistic requirements for effective output tasks. Canadian Modern Language Review/La Revue canadienne des langues vivantes, 60(5), 587-609.

Noor, H. (1996). English Syntactic Errors by Arabic Speaking Learners: Reviewed. Scientific Publishing Centre, 14411465 .

Prentza, A. I. (2012). Second language acquisition of complex structures: The case of English restrictive relative clauses. Theory and Practice in Language Studies, 2(7), 1330-1340.

Richards, J. C., \& Schmidt, R. W. (2010). Longman Dictionary of Language Teaching and Applied Linguistics. Longman. Retrieved from http://books.google.com.sa/books?id=886CPgAACAAJ

Shaheen, B. (2013). A comparative study of restrictive relative clauses in Latakian Syrian Arabic and English restrictive relative clauses by first language speakers of Latakian Syrian Arabic. (Doctoral dissertation). University of Essex. Retrieved from http://ling.auf.net/lingbuzz/001769 
Zagood, M., \& Juma, M. (2012). A contrastive study of relativization in English and Arabic with reference to translation pedagogy (Doctoral dissertation). Durham University. Retrieved from http://etheses.dur.ac.uk/3402/

Zhu, L. (2014). A study of syntactic transfer in relative clause learning of Chinese college English majors. Theory and Practice in Language Studies, 4(3), 613-617.

Appendix A

\section{Acceptability Judgment Test Sentences}

\section{Resumptive pronoun use in RRCs}

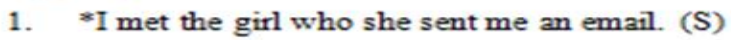

2. *The child hit the dog which it sniffed her leg. (S)

3. *Amanda helped her classmate who she pitied her. (O)

4. *The father fixed the car which his son crashed it. (O)

5. *They assisted the lady who they felt sorry for her. (OP)

6. *The company reconstructed the building which they had been assigned to it. (OP)

Definite RRCs to test the use of overt versus covert using relative markers

7. The judge sentenced the suspect who robbed the shop. (S)

8. They disliked the village that is to the north. (S)

9. *The lady lost the purse was very special. ( $(\varnothing)$

10. *The player could not hit the ball was passing on the right. (S Ø)

11. I dismissed the student who broke the rules. (O)

12. The students did not read the book that the teacher asked them to read. $(O)$

13. The boy ate the snacks you made yesterday. $(O \varnothing)$

14. John emailed the woman he met in the conference. (O $\varnothing)$

15. The lecturer preferred the students who are easy to deal with. (OP)

16. The students liked the class that they can enjoy in. (OP)

17. I lost the card you wrote your number on. (OP $\varnothing$ )

18. I had not washed the mug you drank your coffee from. (OP $\varnothing$ )

Indefinite RRCs to test the use of overt versus covert relative markers

19. I met a lady who talked with me in the train yesterday. (S)

20. My friend bought a cat that has white fur. (S)

21. *The scientist discovered an invention saved the country. (S Ø)

22. *The teacher wamed a child was very noisy. $(S \varnothing)$

23. I invited to my house a friend who I met few months ago. (O)

24. Sarah was reading a book that she expected to be amusing. (O)

25. The snake bit a boy it saw on the farm. (O $\varnothing)$

26. I found an application I could use for translation. (O Ø)

27. That man wanted a car which he could drive to the city. (OP)

28. I preferred a purse that I could keep things in safely. (OP)

29. My friend bought a vase she put a big bouquet in. (OP Ø)

30. I thanked a friend I borrowed some books from. (OP $\varnothing$ )

Preference for using "that"

31. The police caught the thief that stole my mobile. (S) (that)

32. The police caught the thief who stole my mobile. (S)

33. I really needed the money that you spent. (O) (that)

34. I really needed the money which you spent. $(O)$

\section{Distractors}

35. I did not pay attention to what I said as a kid.

36. My brother was very argumentative when he was a teenager.

37. *They had dinner in the restaurant where they eat.

38. *The picture was taken in the station where we met there.

39. *I did know the reason why so many people in the world leaming English.

40. *The building falling down because it was not properly maintained.

41. We drove into the city and spent thirty minutes looking for a place to park.

42. Men like to shop quickly women like to browse.

43. *He was not left a car on the street that he had just bought.

44. Last week we went shopping but did not buy anything.

\section{Repeated sentence}

45. *They assisted the lady who they felt sorry for her. (OP) (5. Repeated) 


\section{Appendix B}

\section{The Acceptability Judgment Test Sample}

\section{Dear participant,}

Your participation in this study is highly appreciated. I am collecting information about the kinds of sentences that second language learners of English find acceptable and those that they do not. The results from this study should help me to better understand how people learn English. I am NOT assessing your knowledge of English. Responses will be collected to discover how people rate the acceptability of English sentences.

* Required

- Name: (optional)

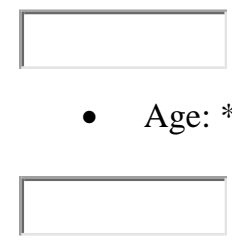

- Gender: *
- Male
○ Female

- Age at first exposure to English language through instruction? *
○ Kindergarten
○ Primary school
○ Intermediate school
o Other:

- Have you been exposed to English language through an immersion-type environment (living in an Englishspeaking country)? *

If yes, please mention your age and for how long.

- For the following sentences, please tell us whether you feel they sound like acceptable English sentences to you, or whether they sound like unacceptable English sentences. Do not think too hard about your decision, and do not go back and change your initial decision. Please rate them from (1-10), where (1) means the sentence seems totally unacceptable and (10) means it looks totally acceptable.

1. I did know the reason why so many people in the world learning English.

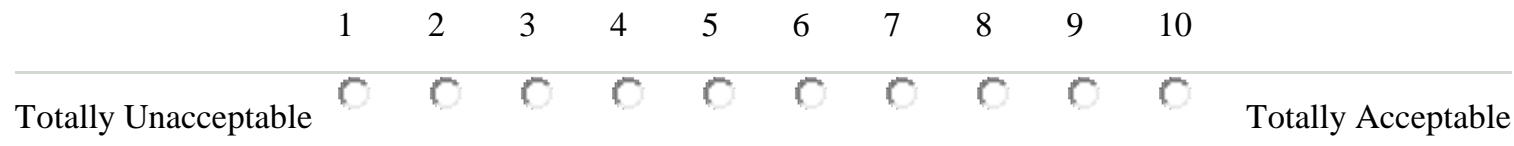

2. Sarah was reading a book that she expected to be amusing.

\begin{tabular}{|c|c|c|c|c|c|c|c|c|c|c|}
\hline 1 & 2 & 3 & 4 & 5 & 6 & 7 & 8 & 9 & 10 & \\
\hline Totally Unacceptable & $C$ & $C$ & $C$ & $C$ & $C$ & $C$ & $C$ & $C$ & $C$ & Totally Acceptable \\
\hline
\end{tabular}

3. John emailed the woman he met in the conference.

\begin{tabular}{llllllllllll|l|l} 
& 1 & 2 & 3 & 4 & 5 & 6 & 7 & 8 & 9 & 10 & \\
\hline Totally Unacceptable & $\mathbf{C}$ & $\mathrm{C}$ & $\mathrm{C}$ & $\mathbf{C}$ & $\mathbf{C}$ & $\mathbf{C}$ & $\mathbf{C}$ & $\mathbf{C}$ & $\mathbf{C}$ & $\mathbf{C}$ & Totally Acceptable
\end{tabular}


4. The scientist discovered an invention saved the country.

Totally Unacceptable

$$
\begin{array}{llllllllll}
1 & 2 & 3 & 4 & 5 & 6 & 7 & 8 & 9 & 10
\end{array}
$$

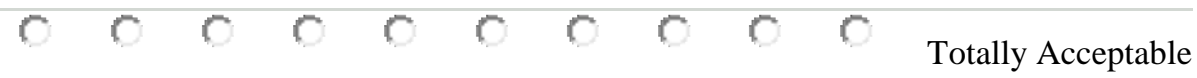

5. I lost the card you wrote your number on.

Totally Unacceptable

$\begin{array}{llllllllll}1 & 2 & 3 & 4 & 5 & 6 & 7 & 8 & 9 & 10\end{array}$

\begin{tabular}{|c|c|c|c|c|c|c|c|c|c|c|c|}
\hline$C$ & $C$ & $C$ & 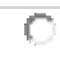 & $r$ & $r$ & $r$ & C & & 3 & C & Totally Acc \\
\hline
\end{tabular}

6. He was not left a car on the street that he had just bought.
12
$\begin{array}{llll}2 & 3 & 4 & 5\end{array}$
Totally Unacceptable
$\begin{array}{lllll}6 & 7 & 8 & 9 & 10\end{array}$
\begin{tabular}{|l|l|l|}
\hline & Totally Acceptable
\end{tabular}

\section{Appendix C}

\section{Results of the Acceptability Judgment Test}

\section{Resumptive Pronoun Use in RRCs}

Table $\mathrm{C} 1$. The frequencies, percentages, and mean ratings for resumptive pronoun items $(\mathrm{N}=100)$

\begin{tabular}{llllllllllllll}
\hline Item & & 1 & 2 & 3 & 4 & 5 & 6 & 7 & 8 & 9 & 10 & M & SD \\
\hline S30 & F & 11 & 4 & 3 & 4 & 4 & 8 & 6 & 6 & 9 & 45 & 7.33 & 3.24 \\
& $\%$ & 11 & 4 & 3 & 4 & 4 & 8 & 6 & 6 & 9 & 45 & & \\
S26 & F & 15 & 8 & 4 & 5 & 5 & 6 & 4 & 13 & 6 & 34 & 6.50 & 3.47 \\
& $\%$ & 15 & 8 & 4 & 5 & 5 & 6 & 4 & 13 & 6 & 34 & & \\
O12 & F & 17 & 4 & 4 & 2 & 6 & 4 & 8 & 12 & 10 & 33 & 6.71 & 3.42 \\
& $\%$ & 17 & 4 & 4 & 2 & 6 & 4 & 8 & 12 & 10 & 33 & & \\
O40 & F & 25 & 11 & 4 & 2 & 7 & 7 & 6 & 6 & 4 & 28 & 5.50 & 3.68 \\
& $\%$ & 25 & 11 & 4 & 2 & 7 & 7 & 6 & 6 & 4 & 28 & & \\
OP39 & F & 28 & 12 & 6 & 2 & 2 & 5 & 6 & 5 & 11 & 23 & 5.29 & 3.75 \\
& $\%$ & 28 & 12 & 6 & 2 & 2 & 5 & 6 & 5 & 11 & 23 & & \\
OP25 & F & 23 & 10 & 10 & 4 & 9 & 2 & 6 & 8 & 11 & 17 & 5.21 & 3.47 \\
& $\%$ & 23 & 10 & 10 & 4 & 9 & 2 & 6 & 8 & 11 & 17 & & \\
\hline
\end{tabular}

\section{Definite RRCs with Overt and Covert Relative Markers}

Table C2The frequencies, percentages, and mean ratings for definite RRC items $(\mathrm{N}=100)$

\begin{tabular}{llllllllllllll}
\hline Item & & 1 & 2 & 3 & 4 & 5 & 6 & 7 & 8 & 9 & 10 & M & SD \\
\hline S 44 & F & 20 & 17 & 11 & 11 & 9 & 4 & 2 & 6 & 6 & 14 & 4.56 & 3.21 \\
& $\%$ & 20 & 17 & 11 & 11 & 9 & 4 & 2 & 6 & 6 & 14 & & \\
S 35 & F & 6 & 5 & 6 & 5 & 4 & 7 & 2 & 11 & 15 & 39 & 7.43 & 3.03 \\
& $\%$ & 6 & 5 & 6 & 5 & 4 & 7 & 2 & 11 & 15 & 39 & & \\
S Ø 24 & F & 7 & 6 & 2 & 4 & 1 & 5 & 5 & 14 & 15 & 41 & 7.68 & 2.97 \\
& $\%$ & 7 & 6 & 2 & 4 & 1 & 5 & 5 & 14 & 15 & 41 & & \\
S Ø 36 & F & 10 & 8 & 3 & 3 & 2 & 12 & 4 & 14 & 9 & 35 & 7.00 & 3.20 \\
& $\%$ & 10 & 8 & 3 & 3 & 2 & 12 & 4 & 14 & 9 & 35 & & \\
O 8 & F & 5 & 4 & 3 & 4 & 4 & 5 & 2 & 7 & 2 & 64 & 8.16 & 2.91 \\
\hline
\end{tabular}




$\begin{array}{llllllllllllll}\text { O 18 } & \text { F } & 3 & 3 & 4 & 2 & 3 & 6 & 4 & 8 & 12 & 55 & 8.30 & 2.59 \\ \text { O Ø 37 } & \% & 3 & 3 & 4 & 2 & 3 & 6 & 4 & 8 & 12 & 55 & & \\ & \text { F } & 9 & 5 & 3 & 5 & 3 & 2 & 1 & 7 & 12 & 53 & 7.76 & 3.22 \\ \text { O Ø } 3 & \% & 9 & 5 & 3 & 5 & 3 & 2 & 1 & 7 & 12 & 53 & & \\ & \text { F } & 8 & 4 & 9 & 3 & 4 & 3 & 3 & 3 & 6 & 57 & 7.62 & 3.30 \\ \text { OP 32 } & \% & 8 & 4 & 9 & 3 & 4 & 3 & 3 & 3 & 6 & 57 & & \\ & \text { F } & 3 & 4 & 5 & 5 & 5 & 5 & 3 & 8 & 13 & 49 & 7.93 & 2.79 \\ \text { OP 11 } & \% & 3 & 4 & 5 & 5 & 5 & 5 & 3 & 8 & 13 & 49 & & \\ & \text { F } & 27 & 12 & 10 & 6 & 9 & 4 & 3 & 2 & 6 & 21 & 4.75 & 3.53 \\ \text { OP Ø 5 } & \% & 27 & 12 & 10 & 6 & 9 & 4 & 3 & 2 & 6 & 21 & & \\ & \text { F } & 5 & 9 & 5 & 3 & 4 & 7 & 5 & 7 & 9 & 46 & 7.44 & 3.13 \\ \text { OP Ø 17 } & \% & 5 & 9 & 5 & 3 & 4 & 7 & 5 & 7 & 9 & 46 & & \\ & \text { F } & 19 & 9 & 11 & 11 & 10 & 4 & 2 & 10 & 4 & 20 & 5.18 & 3.33 \\ & \% & 19 & 9 & 11 & 11 & 10 & 4 & 2 & 10 & 4 & 20 & & \end{array}$

Indefinite RRCs with Overt and Covert Relative Markers

Table $\mathrm{C} 3$. The frequencies, percentages, and mean ratings for indefinite $\mathrm{RRC}$ items $(\mathrm{N}=100)$

\begin{tabular}{|c|c|c|c|c|c|c|c|c|c|c|c|c|c|}
\hline Item & & 1 & 2 & 3 & 4 & 5 & 6 & 7 & 8 & 9 & 10 & $\mathrm{M}$ & SD \\
\hline \multirow[t]{2}{*}{ S14 } & $\mathrm{F}$ & 11 & 8 & 3 & 8 & 6 & 4 & 6 & 12 & 11 & 31 & 6.69 & 3.28 \\
\hline & $\%$ & 11 & 8 & 3 & 8 & 6 & 4 & 6 & 12 & 11 & 31 & & \\
\hline \multirow[t]{2}{*}{ S31 } & $\mathrm{F}$ & 6 & 3 & 7 & 5 & 8 & 6 & 1 & 8 & 10 & 46 & 7.50 & 3.05 \\
\hline & $\%$ & 6 & 3 & 7 & 5 & 8 & 6 & 1 & 8 & 10 & 46 & & \\
\hline \multirow[t]{2}{*}{ S Ø 4} & $\mathrm{~F}$ & 16 & 8 & 5 & 10 & 3 & 7 & 6 & 8 & 8 & 29 & 6.12 & 3.46 \\
\hline & $\%$ & 16 & 8 & 5 & 10 & 3 & 7 & 6 & 8 & 8 & 29 & & \\
\hline \multirow[t]{2}{*}{ S Ø 41} & $\mathrm{~F}$ & 16 & 8 & 5 & 10 & 3 & 7 & 6 & 8 & 8 & 29 & 8.22 & 2.68 \\
\hline & $\%$ & 16 & 8 & 5 & 10 & 3 & 7 & 6 & 8 & 8 & 29 & & \\
\hline \multirow[t]{2}{*}{ O19 } & $\mathrm{F}$ & 22 & 3 & 5 & 7 & 10 & 1 & 4 & 4 & 11 & 33 & 6.16 & 3.65 \\
\hline & $\%$ & 22 & 3 & 5 & 7 & 10 & 1 & 4 & 4 & 11 & 33 & & \\
\hline \multirow[t]{2}{*}{$\mathrm{O} 2$} & $\mathrm{~F}$ & 4 & 3 & 9 & 3 & 5 & 5 & 7 & 10 & 12 & 42 & 7.61 & 2.86 \\
\hline & $\%$ & 4 & 3 & 9 & 3 & 5 & 5 & 7 & 10 & 12 & 42 & & \\
\hline \multirow[t]{2}{*}{ O Ø 28} & $\mathrm{~F}$ & 37 & 14 & 7 & 5 & 6 & 2 & 4 & 11 & 1 & 13 & 4.03 & 3.35 \\
\hline & $\%$ & 37 & 14 & 7 & 5 & 6 & 2 & 4 & 11 & 1 & 13 & & \\
\hline \multirow[t]{2}{*}{ O Ø 13} & $\mathrm{~F}$ & 5 & 6 & 6 & 6 & 4 & 1 & 8 & 5 & 12 & 47 & 7.59 & 3.07 \\
\hline & $\%$ & 5 & 6 & 6 & 6 & 4 & 1 & 8 & 5 & 12 & 47 & & \\
\hline \multirow[t]{2}{*}{ OP23 } & $\mathrm{F}$ & 4 & 11 & 11 & 7 & 10 & 7 & 7 & 8 & 4 & 31 & 6.38 & 3.12 \\
\hline & $\%$ & 4 & 11 & 11 & 7 & 10 & 7 & 7 & 8 & 4 & 31 & & \\
\hline \multirow[t]{2}{*}{ OP10 } & $\mathrm{F}$ & 12 & 5 & 4 & 11 & 4 & 5 & 8 & 8 & 10 & 33 & 6.68 & 3.29 \\
\hline & $\%$ & 12 & 5 & 4 & 11 & 4 & 5 & 8 & 8 & 10 & 33 & & \\
\hline \multirow[t]{2}{*}{ OP Ø 42} & $\mathrm{~F}$ & 21 & 11 & 16 & 9 & 9 & 3 & 6 & 7 & 5 & 13 & 4.63 & 3.16 \\
\hline & $\%$ & 21 & 11 & 16 & 9 & 9 & 3 & 6 & 7 & 5 & 13 & & \\
\hline \multirow[t]{2}{*}{ OP Ø 21} & $\mathrm{~F}$ & 15 & 10 & 11 & 7 & 9 & 4 & 8 & 8 & 7 & 21 & 5.58 & 3.32 \\
\hline & $\%$ & 15 & 10 & 11 & 7 & 9 & 4 & 8 & 8 & 7 & 21 & & \\
\hline
\end{tabular}


Preference for Using "That"

Table $\mathrm{C} 4$.The frequencies, percentages, and mean ratings for "that" preference items $(\mathrm{N}=100)$

\begin{tabular}{llllllllllllll}
\hline Item & & 1 & 2 & 3 & 4 & 5 & 6 & 7 & 8 & 9 & 10 & $\mathrm{M}$ & $\mathrm{SD}$ \\
\hline that 29 & $\mathrm{~F}$ & 11 & 3 & 4 & 4 & 3 & 6 & 2 & 6 & 9 & 52 & 7.59 & 3.27 \\
\multirow{4}{*}{ who 9} & $\%$ & 11 & 3 & 4 & 4 & 3 & 6 & 2 & 6 & 9 & 52 & & \\
& $\mathrm{~F}$ & 4 & 3 & 5 & 3 & 2 & 3 & 2 & 3 & 4 & 71 & 8.49 & 2.79 \\
\multirow{3}{*}{ that 38} & $\%$ & 4 & 3 & 5 & 3 & 2 & 3 & 2 & 3 & 4 & 71 & & \\
& $\mathrm{~F}$ & 7 & 3 & 4 & 2 & 5 & 3 & 5 & 6 & 11 & 54 & 7.98 & 2.96 \\
which 15 & $\%$ & 7 & 3 & 4 & 2 & 5 & 3 & 5 & 6 & 11 & 54 & & \\
& $\mathrm{~F}$ & 10 & 8 & 5 & 4 & 8 & 5 & 2 & 10 & 7 & 41 & 6.94 & 3.36 \\
& $\%$ & 10 & 8 & 5 & 4 & 8 & 5 & 2 & 10 & 7 & 41 & & \\
\hline
\end{tabular}

Age

Table C5. One-way ANOVA to determine the differences between age groups

\begin{tabular}{lllllll}
\hline $\begin{array}{l}\text { Tested } \\
\text { Aspects }\end{array}$ & Source of Variation & $\begin{array}{l}\text { Sum of } \\
\text { Squares }\end{array}$ & $d f$ & Mean Square & $F$ & $P$-value \\
\hline Resumptive & Between group & 1280.670 & 2 & 640.335 & 2.548 & Not Sig. \\
Pronoun & Within group & 24378.17 & 97 & 251.321 & & \\
Definite RRCs & Between group & 721.016 & 2 & 360.508 & 0.985 & Not Sig. \\
& Within group & 35508.374 & 97 & 366.066 & & \\
Indefinite & Between group & 392.076 & 2 & 196.038 & 0.593 & Not Sig. \\
RRCs & Within group & 32055.314 & 97 & 330.467 & & \\
"That" & Between group & 246.502 & 2 & 123.251 & \multirow{2}{*}{1.405} & Not Sig. \\
Preference & Within group & 8507.498 & 97 & 87.706 & & \\
Object & Between group & 434.396 & 2 & 217.198 & 3.737 & 0.05 \\
& Within group & 5638.244 & 97 & 58.126 & & \\
\hline
\end{tabular}

